\title{
IMPLEMENTASI CUSTOMER RELATIONSHIP MANAGEMENT PADA APLIKASI E-COMMERCE UNTUK MEMBANTU MENYELEKSI BUSANA MUSLIM SESUAI KARAKTERISTIK KONSUMEN
}

\author{
Yuliani Tanjung ${ }^{1}$, Semlinda Juszandri Bulan ${ }^{2}$ \\ ${ }^{1}$ Teknik Informatika, STIKOM Uyelindo \\ email: ranliem4@gmail.com \\ ${ }^{2}$ Sistem Informasi, STIKOM Uyelindo \\ email: semlinda@yahoo.com
}

\begin{abstract}
Daya Abadi Shop is a place that provides various products muslim fashion to Muslim women. The sales strategy which is in use now still wearing convensional system. The first is marketing still no media promotion. The problem, the clerk having difficulties to explain the appropriate fashion characteristics, and third from aspect of where the sales transaction data and customer data is still the recording manually. The purpose of this research is to implement E-Commerce and Customer Relationship Management in selling of muslim fashion on Daya Abadi Fashion Shop. The research methodology used was qualitative research. Website Development method E-Commerce based on Customer Relationship Management made adjust with research procedures. The approach method with structured and analysis tools in the form of system design document flow, context diagram, data flow diagram and design of the proposed database form entity relationship diagram. While the creation of the software in this thesis, the writer uses PHP and Adobe Dreamwaver CS3 and MySQL databases. The research results show that the E-Commerce based on Customer Relationship Management can help the Daya Abadi Shop in the selling of muslim fashion.
\end{abstract}

Keywords: customer relationship management, muslim fashion, e-commerce

\section{PENDAHULUAN}

Persaingan bisnis sekarang ini semakin meningkat sehingga banyak pengusaha mencari cara untuk mempertahankan pelanggan atau memperoleh pelanggan baru. Oleh karena itu, perusahaan tersebut harus menggunakan strategi yang tepat. Salah satu konsep yang ditawarkan adalah CRM (Customer Relationship Management) yang memiliki tujuan untuk meningkatkan kepuasaan pelanggan dan terutama untuk mendapatkan (acquire), mempertahankan (retain), meningkatkan (enchance) jumlah pelanggan perusahaan [1]. Selain itu faktor penting yang harus dipertimbangkan oleh perusahaan dalam persaingan bisnis yaitu membangun relasi yang erat antara perusahaan dengan para pelanggannya. Salah satu penerapan e-commerce berbasis CRM pada bidang penjualan busana.

Toko Daya Abadi Fashion adalah toko yang bergerak di bidang penjualan berbagai macam produk, khususnya wanita muslimah seperti busana muslim dan kerudung (jilbab). Toko Daya Abadi Fashion berlokasi di jalan K.H. Ahmad Dahlan No. 19 Kupang. Sistem penjualan yang dipakai sekarang masih memakai sistem konvensional. Dilihat dari segi pemasaran belum tersedia media untuk memberikan informasi tentang produk busana muslim, sehingga informasi tersebut disampaikan hanya dari pelanggan satu ke pelanggan yang lainnya. Dilihat dari segi pelayanan yaitu pengawai mengalami kesulitan untuk menjelaskan kepada pelanggan tentang busana muslim yang sesuai dengan karakteristik pelanggan tanpa meninggalkan aturan syari'at Islam. Dilihat dari segi penjualan, data transaksi dan data pelanggan masih bersifat pencatatan manual. Strategi penjualan seperti ini kurang efektif karena membuat pelanggan kurang memperoleh informasi baru tentang produk tersebut, sehingga membuat pelanggan mudah untuk beralih ke toko lain yang 
menawarkan informasi tentang produk terbaru.

Melihat permasalahan tersebut, pemilik Toko Daya Abadi Fashion menyadari bahwa sistem yang bersifat non teknologi ini kurang menguntungkan, sehingga dibutuhkan sistem komputerisasi dengan menggunakan strategi yang tepat dalam pengolahan data pelanggan serta memperlancarkan sistem penjualan produk busana muslim yang sesuai dengan karakteristik pelanggan. Strategi ini diharapkan mampu menjalankan proses bisnis yang mengoptimalkan pemasaran dan penjualan, pelayanan ini dikenal dengan CRM atau Customer Relationship Management. Konsep Customer Relationship Management yang ditekankan antara lain untuk memperoleh pelanggan baru (aquire), meningkatkan hubungan dengan pelanggan (enhance), dan mempertahankan pelanggan (retain). Dengan penerapan E-Commerce berbasis Customer Relationship Management diharapkan dapat memperluas peluang bisnis penjualan pada Toko Daya Abadi Fashion, sehingga masalah yang terjadi dalam sistem manual tersebut dapat diminimalisir serta mempermudah pelanggan dalam memilih busana muslim sesuai dengan karakteristik yang diinginkan dan mempererat hubungan antara pelanggan dan Toko Daya Abadi Fashion sebagai penyedia busana muslim.

Berdasarkan uraian tersebut, maka penulis tertarik membangun website dengan judul implementasi customer relationship management pada aplikasi e-commerce untuk membantu menyeleksi busana muslim sesuai karakteristik konsumen

\section{LANDASAN TEORI}

\subsection{Customer Relationship Management}

Customer Relationship Management (CRM) dalam bahasa Indonesia dapat diartikan Manajemen Hubungan Pelanggan (MHP). Secara etimologis CRM berasal dari tiga kata yaitu customer atau pelanggan berarti seseorang yang berulang kali atau secara teratur melakukan pembelian kepada seorang pedagang. Relationship atau hubungan adalah bentuk komunikasi dua arah antara pembeli dan penjual. Management atau manajemen berarti pengelolaan. Secara harafiah CRM merupakan pengelolaan hubungan dua arah antara suatu perusahaan dengan orang yang menjadi pelanggan di perusahaan tersebut [2].

Customer Relationship Management adalah strategi membangun relasi yang erat antara perusahaan dengan para pelanggannya. Strategi ini menganjurkan agar perusahaan membuka saluran komunikasi yang mudah sehingga pelanggan dapat merasakan kedekatan dengan pihak perusahaan. Dengan demikian, perusahaan akan memperoleh manfaat dari penerapan Customer Relationship Management ini, yakni memiliki pelanggan yang loyal [3].

\subsection{Tujuan $C R M$}

Menurut [4], ada beberapa tujuan yang dicapai dari penerapan Customer Relationship Management yaitu:

1. Menggunakan hubungan yang sudah terbentuk untuk meningkatkan pendapatan. Pendapatan perusahaan yang tepat mengenai pelanggan dapat berguna untuk memaksimalkan hubungan pelanggan dan perusahaan melalui penjualan produk dengan kualitas yang baik (up-selling), penjualan produk komplemen (cross-selling), dan mempertahankan pelanggan untuk meningkatkan keuntungan.

2. Menggunakan informasi dalam memberikan pelayanan dengan baik, sehingga perusahaan dapat menghemat waktu pelanggan dan mengurangi ketidakpuasan. Sebagai contoh, pelanggan seharusnya tidak mengulangi informasi kepada berbagai divisi berulang-ulang. Pelanggan selalu mendapatkan informasi terbaru dari perusahaan tersebut.

3. Dengan tersebarnya kontak elanggan, lebih banyak penawaran terlihat dengan transaksi penjualan.

\subsection{Manfaat $C R M$}

Menurut [4], ada beberapa manfaat yang dicapai dari penerapan Customer Relationship Management yaitu:

1. Mendorong loyalitas pelanggan 
Aplikasi CRM memastikan perusahaan untuk memanfaatkan informasi dari setiap titik kontak dengan pelanggan, baik melalui web, call center, atau melalui staf pelayanan di lapangan. Dengan adanya konsistensi dan kemudahan dalam mengakses dan menerima informasi, maka bagian pelayanan akan memberikan layanan yang lebih baik kepada pelanggan dengan memanfaatkan berbagai informasi penting mengenai pelanggan tersebut.

2. Mengurangi biaya

Penerapan CRM memungkinkan pelayanan terhadap pelanggan memiliki skema informasi yang spesifik dan terfokus, serta dapat menargetkan pelayanan pada pelanggan yang tepat dan pada saat yang tepat. Dengan demikian, biaya yang dikeluarkan dapat digunakan secara teratur dan tidak sia-sia.

3. Meningkatkan efisiensi operasional

Kemudahan proses penjualan dan layanan dapat mengurangi resiko menurunnya kualitas pelayanan dan mengurangi bebas cash flow.

4. Peningkatan time to market

Penerapan CRM akan memungkinkan perusahaan mendapatkan informasi mengenai pelanggan seperti data trend pembelian oleh pelanggan yang dimanfaatkan perusahaan dalam menentukan waktu yang tepat dalam memasarkan suatu produk.

5. Peningkatkan pendapatan

Penerapan CRM yang tepat akan meningkatkan loyalitas pelanggan, mengurangi biaya dan meningkatkan efesiensi operasional.

\subsection{Riset Terkait}

[5] membangun sebuah Sistem Informasi Manajemen Beras pada Penggilingan Padi Sahabat Kita yang berbasis Customer Relationship Management. Manfaat dari penelitian ini adalah (a) dapat memberikan kontribusi secara langsung dan mempermudah bagian pengelola perusahaan penggilingan padi dengan proses management data yang menggunakan sistem komputerisasi, (b) dengan adanya Customer Relationship Management yang diterapkan dalam sistem, dapat menjadi suatu kebijakan baru dalam menunjang, meningkatkan keuntungan atau pendapatkan nilai daya saing, (c) dapat membantu mempermudah dalam melihat jejak data pelanggan atau pelanggan lain yang ada pada perusahaan penggilingan padi Sahabat Kita. Aplikasi berbasis Customer Relationship Management ini dirancang untuk mengatasi permasalahan mengenai pembelian, penjualan dan distribusi beras sehingga memudahkan admin dalam memanajemen data, memberikan informasi, memperoleh pelanggan baru, mempertahankan serta meningkatkan dan menjaga loyalitas pelanggan.

[6] melakukan penelitian tentang Customer Relationship Management pada Sistem Manajemen Penjualan Sirip Ikan Hiu pada UD Adil. Manfaat dari penelitian ini adalah (a) mampu menyajikan Informasi harga sirip ikan hiu berdasarkan kategori sirip ikan hiu yang langsung diketahui oleh nelayan melalui SMS, (b) memberi kemudahan bagi pegawai dalam memantau dan mengevaluasi proses penjualan dan pembelian sirip ikan hiu, (c) perusahaan dapat menjaga loyalitas dengan para nelayan yang telah dan menarik nelayan baru dengan cara memberikan penawaran yang menarik melalui SMS. Hasil penelitian ini yaitu dengan memanfaatkan customer relationship management maka perusahaan dapat meningkatkan efisiensi dn efektivitas target merketing dengan memberikan informasi yang lengkap dan mendukung proses pembelian dan penjualan kepada pelanggan dengan cara memberikan penawaran yang menarik melalui SMS.

\section{METODE PENELITIAN}

\subsection{Pendekatan Penelitian}

Dalam penelitian ini penulis menggunakan metode penelitian kualitiatif adalah sebuah metode penelitian yang efektif untuk menggambarkan atau mendeskripsikan fenomena-fenomena yang ada [7]. Jenis penelitian kualitatif yang digunakan pada penelitian ini dimaksudkan untuk memperoleh informasi mengenai strategi penjualan dan pemasaran yang ada pada Toko Daya Abadi Fashion secara mendalam dan komprehensif. Selain itu, dengan 
pendekatan kualitatif diharapkan dapat memberikan solusi dari permasalahan yang dihadapi pada Toko Daya Abadi Fashion.

\subsection{Prosedur Penelitian}

Prosedur penelitian yaitu tahapantahapan yang dilalui oleh peneliti dimulai dari tahap pengumpulan data sampai pada tahap kesimpulan, yang berbentuk sebuah alur yang sistematis. Prosedur penelitian ini digunakan sebagai pedoman dalam pelaksanaan penelitian agar hasil yang dicapai dengan tujuan yang telah ditentukan sebelumnya. Alur prosedur penelitian dapat dilihat pada Gambar 1.

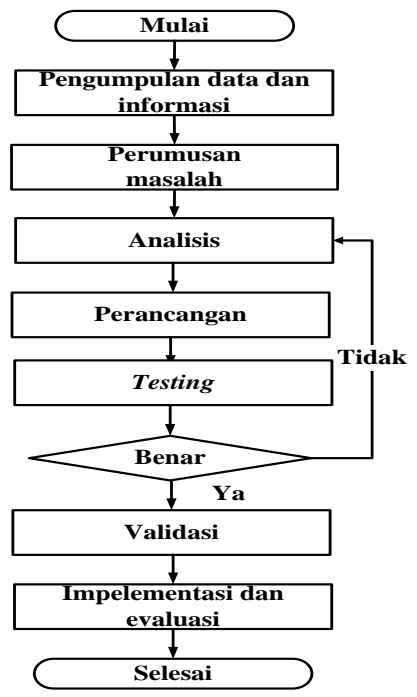

Gambar 1. Prosedur Penelitian

Penjelasan dari Gambar 1 Prosedur Penelitian adalah sebagai berikut:

1) Pengumpulan data dan informasi

Pada tahap ini penulis mengumpulkan data dan informasi untuk mendukung pelaksanaan penelitian dengan menggunakan beberapa teknik pengumpulan data dan informasi antara lain melakukan observasi secara langsung pada Toko Daya Abadi Fashion be:rupa koleksi busana muslim, cara transaksi, dokumentasi dan mencari informasi yang terkait dengan judul dan wawancara dengan pemilik Toko Daya Abadi Fashion.

2) Perumusan Masalah

Pada tahap ini penulis mengajukan pertanyaan kepada pemilik toko untuk mendapatkan informasi terkait dengan masalah, setelah itu peneliti memberikan solusi untuk mengatasi permasalahan yang ada pada Toko Daya Abadi Fashion.

3) Analisis

Pada tahap ini penulis menguraikan data dan informasi ke dalam bentuk komponen-komponen yang bertujuan untuk menganalisis masalah yang ada, dan hambatan-hambatan yang terjadi mengarah pada sehingga mengarah kepada solusi untuk memperbaiki kearah yang lebih baik sesuai kebutuhan.

4) Perancangan

Pada tahap ini penulis membangun sebuah rancangan untuk memenuhi kebutuhan yang ditentukan selama tahapan perumusan masalah. Hasilnya berupa spesifikasi rancangan yang sangat rinci sehingga mudah diwujudkan pada saat pemrograman.

5) Testing

Pada tahap ini dilakukan pengujian untuk memastikan website ini sudah bebas dari kesalahan (error) atau belum. Jika website ini masih terdapat kesalahan (error), maka website ini harus kembali lagi ke tahap analisis dan jika website ini sudah sesuai dengan Perancangan maka akan lanjut ke tahap berikutnya yaitu validasi.

6) Validasi

Pada tahap ini dilakukan validasi guna memastikan website Customer Relationship Management yang digunakan telah sesuai dengan tahap perancangan dan telah melalui testing sehingga siap untuk digunakan.

7) Implementasi dan evaluasi

Tahap ini penulis akan di mengimplementasikan ke dalam bahasa pemrograman. Kemudian dilakukan evaluasi untuk memastikan apakah telah sesuai dengan tujuan yang dibuat dan website ini masih bisa dikembangkan pada penelitian selanjutnya.

\subsection{Analisa sistem yang sedang berjalan}

Analisis sistem yang sedang berjalan yaitu analisis tentang penjualan pada Toko Daya Abadi Fashion yang masih menggunakaan sistem konvesional. Dilihat dari segi pemasaran belum tersedia media 
untuk memberikan informasi tentang produk busana muslim, sehingga informasi tersebut hanya disampaikan dari pelanggan satu ke pelanggan yang lainnya. Dilihat dari segi pelayanan yaitu pengawai mengalami kesulitan untuk menjelaskan kepada pelanggan tentang busana muslim yang sesuai dengan karakteristik pelanggan tanpa meninggalkan aturan syari'at Islam. Dilihat dari segi penjualan dimana data transaksi dan data pelanggan masih bersifat pencatatan manual. Strategi penjualan seperti ini kurang efektif karena membuat pelanggan kurang memperoleh informasi baru tentang produk busana muslim yang dijual sehingga, membuat pelanggan mudah untuk beralih ke toko lain yang menawarkan informasi tentang produk terbaru.

\subsection{Deskripsi sistem yang diusulkan}

Sistem yang diusulkan dapat membantu Toko Daya Abadi Fashion tidak mengalami perubahan dari sistem yangg sedang berjalan, hanya berbeda dalam penggunaan sistem komputerisasi yang dapat membantu proses memasukan, mengubah dan menghapus data serta memperluas cakupan penjualan busana muslim yang sesuai dengan karakteristik pelanggan. Hal ini dikarenakan sistem yang diusulkan dapat diakses di manapun dan kapanpun, serta sebagai media interaksi antara toko dan pelanggan untuk menjaga dan membantu relasi yang lebih baik. Sistem yang digunakan berupa client server, di semua data yang disimpan di server. Pelanggan dapat mengakses data di server menggunakan media internet. Data masukkan yang dikirim oleh pelanggan akan disimpan dan diolah di server kemudian akan dikirim kembali ke pelanggan yang melakukan permintaan. Untuk lebih jelas perhatikan Gambar 2 berikut ini.

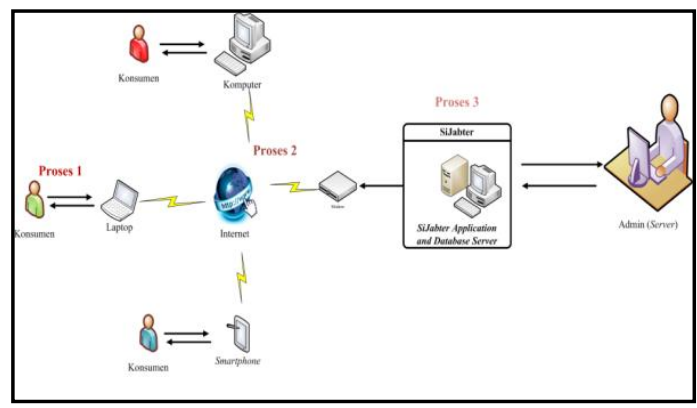

\section{Gambar 2. Arsitektur Toko Daya Abadi}

\subsection{Perancangan}

Pada tahap ini peneliti membangun sebuah rancangan untuk memenuhi kebutuhan yang ditentukan selama tahapan perumusan masalah. Berikut merupakan tahapan perancangan yang meliputi: Entity Relationship Diagram (ERD), Diagram Konteks, dan Data Flow Diagram (DFD) level 0.

\section{Entity Relationship Diagram}

Entity Relationship Diagram biasa digunakan untuk menggambarkan insial atau identitas dari desain basis data. Setiap table memiliki field atau kolom dan memiliki primary key untuk mengidentifikasi sebuah record. Entity Relationship Diagram berisi komponen-komponen himpunan entitas dan himpunan relasi yang masing-masing dilengkapi dengan beberapa atribut, yang mana komponen tersebut dapat digambarkan secara sistematis menggunakan Entity Relationship Diagram. ERD dari website Daya Abadi Fashion pada Gambar 3 sebagai berikut.

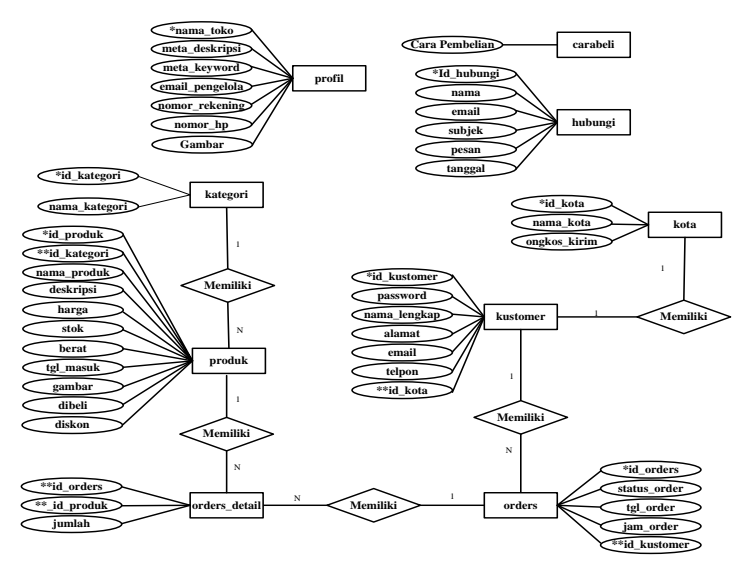

Gambar 3. Entity Relationship Diagram

\section{Diagram Konteks}

Diagram konteks adalah sebuah diagram sederhana yang menggambarkan hubungan antara entitas luar dengan input dan output sistem. Dalam pembuatan diagram konteks, perlu adanya pencatatan data yang masuk ke dalam sistem beserta sumbernya dan informasi yang dihasilkan sistem beserta 
tujuan. Berikut ini merupakan diagram konteks dari E-Commerce Toko Daya Abadi Fashion.

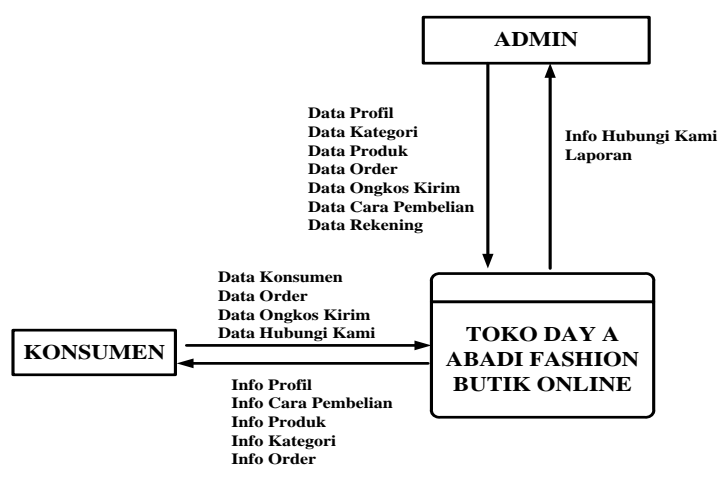

Gambar 4. Diagram Konteks

\section{Diagram Flow Diagram}

Data flow diagram memberikan deskripsi yang mendetail terhadap masalah yang dipecahkan oleh perangkat lunak. DFD dikembangkan untuk membantu menganalisa aliran data dan merancang sistem. DFD mempunyai proses dasar yang berisi entitas luar (external entity), proses (process), objek data (data object) dan penyimpanan data (database).

DFD level 0 merupakan penggambaran Hierarchy Input Process Output (HIPO) yang lebih rinci. Pada DFD level 0 akan menggambarkan interaksi antara sistem yang dikembangkan dengan entitas luar secara umum.

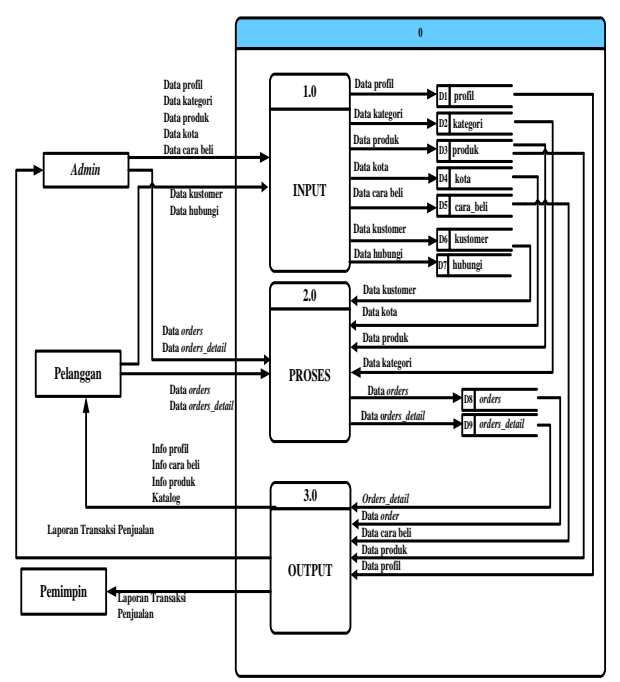

Gambar 5. DFD level 0
Aplikasi E-commerce ini dibangun menggunakan software Dreamweaver dengan bahasa pemrograman PHP dan database MySQL.

\subsection{Antarmuka login}

Antarmuka login admin ini berfungsi sebagai security dan merupakan halaman untuk melakukan proses login sebelum mengakses halaman administrator Daya Abadi Fashion. Halaman tersebut hanya bisa diakses jika pengguna (pegawai) mengisi username dan password dengan benar.

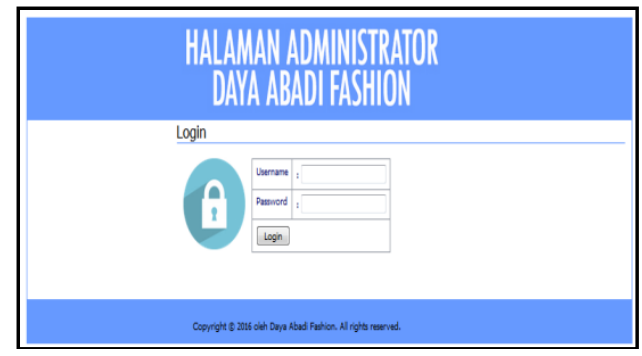

Gambar 6. Antarmuka login

4.2. Antarmuka pengolahan orders_detail pada admin

Gambar 7 berikut ini menampilkan antarmuka pengolahan orders_detail. Pada proses orders_detail ini admin dapat melihat daftar pemesanan dari pelanggan yang baru saja melakukan pemesanan barang, daftar pemesanan ini meliputi No. order, waktu order, produk yang dibeli beserta data pelanggan. Admin memiliki tugas untuk melihat status order dari pelanggan. Jika pelanggan baru saja melakukan proses pemesanan, maka status ordernya adalah baru. Jika pelanggan telah melakukan konfirmasi bukti pembayaran berupa gambar melalui whatsapp dan BBM, maka admin dapat mengubah status order pelanggan dari status baru ke status lunas. Sedangkan, jika pelanggan belum melakukan konfirmasi bukti pembayaran selama tiga hari, maka admin dapat mengubah status baru ke status batal.

\section{HASIL DAN PEMBAHASAN}




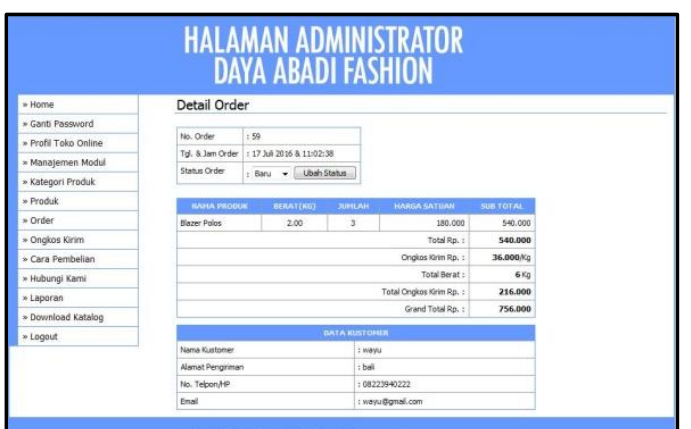

Gambar 7. Antarmuka pengolahan data orders_detail pada admin

4.3. Antarmuka pengolahan pelanggan

Gambar 8 berikut ini menampilkan antarmuka pengolahan data pelanggan. Data tersebut akan diisi oleh pelanggan setelah selesai memasukkan produk ke dalam keranjang belanja. Bukti pemesanan barang akan dikirim ke email pelanggan. Bagi pelanggan baru dapat melakukan registrasi terlebih dahulu dengan memasukkan nama lengkap, password, alamat pengiriman, telpon/ Hp, email, kota tujuan dan captcha. Sedangkan pelanggan lama dapat melakukan login dengan mengisi email dan password. Antarmuka ini didesain dengan konsep simple dan kombinasi warna yang minimalis sehingga dapat memberikan kenyamanan kepada admin saat pengolahan produk.

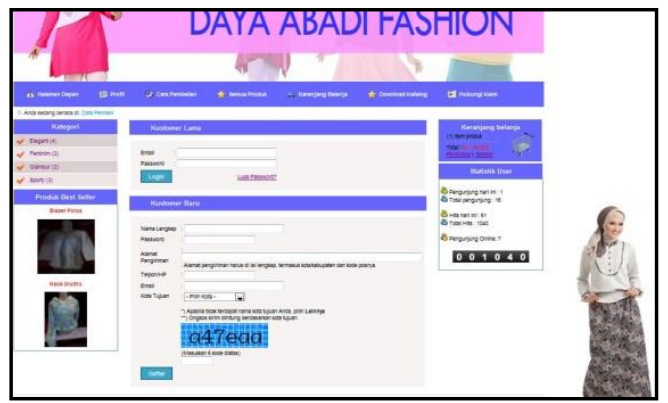

Gambar 8. Antarmuka pengolahan data pelanggan

\subsection{Antarmuka pengolahan data orders}

Gambar 9 berikut ini menampilkan antarmuka pengolahan data order. Pelanggan dapat memilih produk sesuai dengan keinginan. Jika ingin melakukan pemesanan atau pembelian, pelanggan dapat data memillih tombol beli. Produk secara otomatis akan dimasukkan ke keranjang belanja. Setelah selesai menentukan jumlah produk yang dimasukkan ke keranjang belanja data tersebut akan diisi oleh pelanggan selesai berbelanja. Bukti pemesanan barang akan dikirim ke email pelanggan. Bagi pelanggan baru harus melakukan registrasi terlebih dahulu. Proses pengolahan data tersebut meliputi edit, hapus dan tambah.

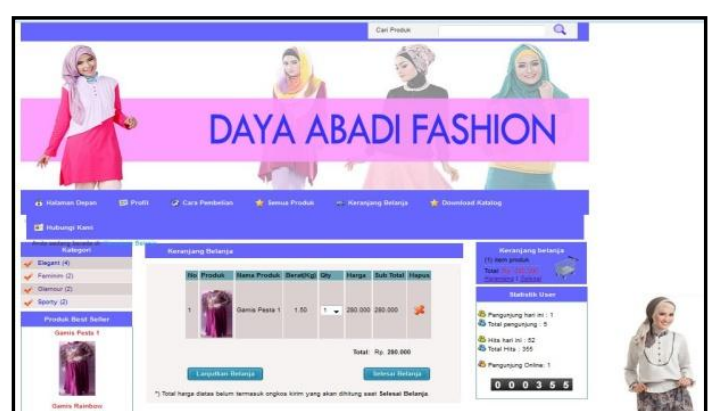

Gambar 9. Antarmuka pengolahan data orders

\subsection{Katalog}

Gambar 10 menunjukkan katalog produk busana muslim sesuai karakeristik. Katalog ini akan diterbitkan setiap bulan dan dapat diunduh secara gratis oleh pelanggan.

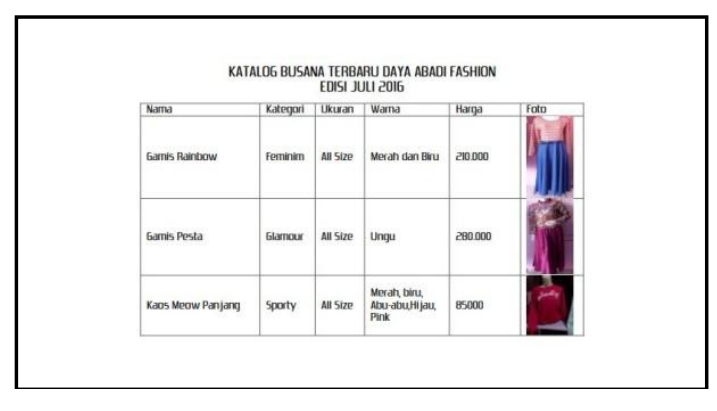

Gambar 10. Katalog

\subsection{Laporan}

Gambar 11 menunjukkan halaman pengolahan laporan penjualan merupakan halaman yang digunakan oleh admin untuk melakukan pengelolaan laporan penjualan yang akan ditampilkan dengan memasukkan tanggal awal dan akhir agar bisa didownload. 


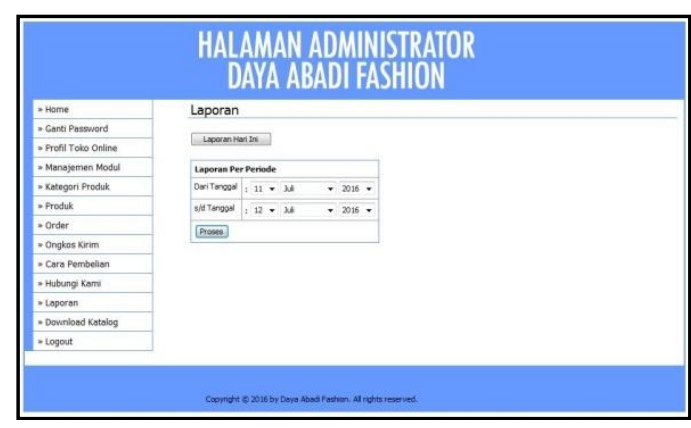

Gambar 11. Antarmuka halaman laporan penjualan

Gambar 12 berisi rekapan laporan penjualan Daya Abadi Fashion berdasarkan tanggal yang yang dimasukkan oleh admin. Hasil cetak laporan ini dapat di-download dalam bentuk pdf.

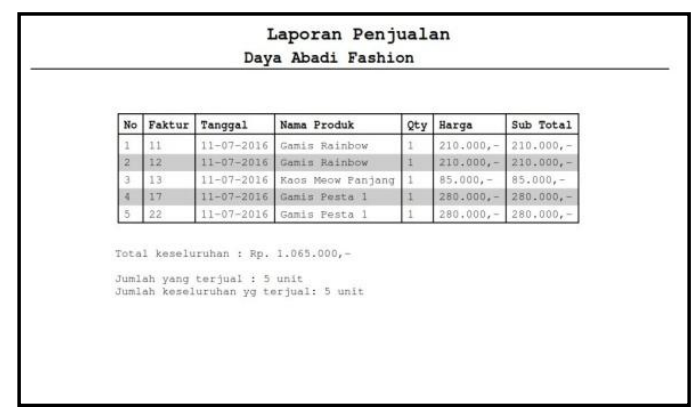

Gambar 12. Cetak laporan

\section{KESIMPULAN}

Dengan adanya implementasi CRM pada aplikasi E-Commerce padaToko Daya Abadi Fashion yang maka dapat dapat membantu konsumen dalam menyeleksi busana muslim yang sesuai dengan karakteristik konsumen.

\section{REFERENSI}

[1] Zikmud, W.G. 2003. Customer Relationship Management: Integrating Marketing Strategy and Information Tecnology. Jhon Willey \& Sons Inc. Amerika (US).

[2] Heru, A.D. 2003. Pengenalan Customer Relationship Management (CRM). http://www.kuliah-umumilmu-komputer. com. Diakses tanggal 6 Mei 2016.

[3] Oetomo, B.S.D, John, P.S, dan Andreas A.S. 2003. I-CRM Membina Relasi dengan Konsumen. Andi. Yogyakarta.

[4] Kalakota, R. dan Robinson, M. 2001. EBusiness 2.0 Roadmap for Success. Addsion Wesley Longman Inc. Massachusetts (US).

[5] Moreira, C.O. 2015. Sistem Informasi Management Beras pada Penggilingan Padi Sahabat Kita berbasis Customer Relationship Management. Skripsi: STIKOM Uyelindo. Kupang.

[6] Paty, N. 2015. Customer Relationship Management pada Sistem Management Penjualan Sirip Ikan Hiu Pada UD. Adil Utama. Skripsi: STIKOM Uyelindo. Kupang.

[7] Arikunto S. 2010. Prosedur Penelitian Suatu Pendekatan Praktik. Rineka Cipta. Jakarta. 